\title{
ANALYTICAL STUDY FOR MEASURING THE ELECTROMAGNETIC RADIATION OF THE GSM SYSTEM IN URBAN AREAS
}

\author{
Murad A.A.Almekhlafi \\ Department of Electrical Engineering - Division Communication Engineering, \\ Sana'a University- Faculty of Engineering, Sana'a, Yemen.
}

\begin{abstract}
This paper discusses three subjects. In the first section Study And Evaluation Of Mobile Network While in the second section, Radiated Power Density ability of cellular stations. In the third section compare the results with the International Standards and safety limits recommended by the ICNIRP to ensure compliance with the terms and the extent of their impact on human health, on the other hand, through the results of theoretical analysis and benchmark Mathematical Analysis And Practical Measurement.
\end{abstract}

\section{KEYWORDS}

Electromagnetic Radiation;Global System for Mobile communications (GSM) ;Code;Urban area; Measurement;Received Power; Radiation pattern ;Power Density;Equipment Spectrum Analyzer.

\section{INTRODUCTION}

At the present time, we are in twenty first century live in an age of technological revolution, the rapid evolution of technology, followed by a similar development in the processes of creation and artistic creativity for different products, you know technology as: application of scientific theories in the productive and industrial sector, technology is a method or combination of methods, techniques, or technical systems separate or sequential or complementary to the production of things in order to be used according to the needs of people in their lives and to achieve their desires to fulfill the purpose for which they were designed. This is attached to the human element and being linked to the environment and the community to protect public health. It must be of a standard consistent with the public concern over the health effects of exposure to electromagnetic fields.

The Mobile Communication Devices (MCD)are sources which may cause strong exposure to RF-EMF to the human headi $n$ daily lives.Possible health hazards of the Electro magnetic fields from mobile communication devices have become of concern and enormous efforts have been made to clarify the possible hazards and risks of expo- sure associated with this technology. The research is still continuing but the evidence reported so far indicates few effects that could possibly damage human health seriously.Only slight changes in physiological function in the brain may exist but the variation of the data is too large to believe that the exposure actually has the potential to affect function.Overall,the health risk, if any,at an individual level, would be very low in consideration of the available 
evidence.However, if mobile phone fields were actually hazardous, the very large number of mobile phone users could mean that,even if the individual risk were very low, the impact on public health could be considerable.This is the most important point that warrants the large studies promoted by those international and national organizations involved in this issue [12]. Follett ELF-EMF Mobile phones in relation to health are now being studied with great effort and in comprehensive studies, particularly in the involved in this issueELF-EMF Mobile phones in relation to health are now being studied with great effort and in comprehensive studies, particularly in the Interphone Study. The results of the Interphone Study will soon become available. It has to be doubted, however, that the results will be entirely conclusive, as the first results from published national components of this study already raise a number of questions with respect to the potential of bias. Another limitation is that also in the current studies, long-term mobile phone users have had hardly more than 10 years of regular use of mobile phones, which still may be a relatively short latency period, particularly for slowly growing benign tambours. Among those long-term users, most were initially users of analogue mobile phone and thus, the number of long-term users of the digital technology is even smaller. As part of our humanitarian mission and the first scientific degree of second degree research work to fill important gaps in knowledge, as it facilitates the development of internationally accepted standards to reduce exposure to electromagnetic radiation.

In this sense, the goal of this research is to; analytical study for measuring the electromagnetic radiation of the CDMA \& GSM system in urban areas, through the results that have been obtained through theoretical analysis, and a standard cellular network in the city of Sanaa, the capital of the Republic of Yemen as a case study. Mathematical Analysis And Practical Measurement, and according to our plan, this research is the first step of a four-step, the second step we will do the same three axes but in the Suburban Area region, and the third step in the Open Area region, and the fourth step will be as a comparison between these regions through the results of theoretical analysis and record ,and compare it with Security and safety standards, and this is the first study in the Republic of Yemen.

\section{VARIOUS STEPS CARRIED-OUT IN THIS RESEARCH PAPER}

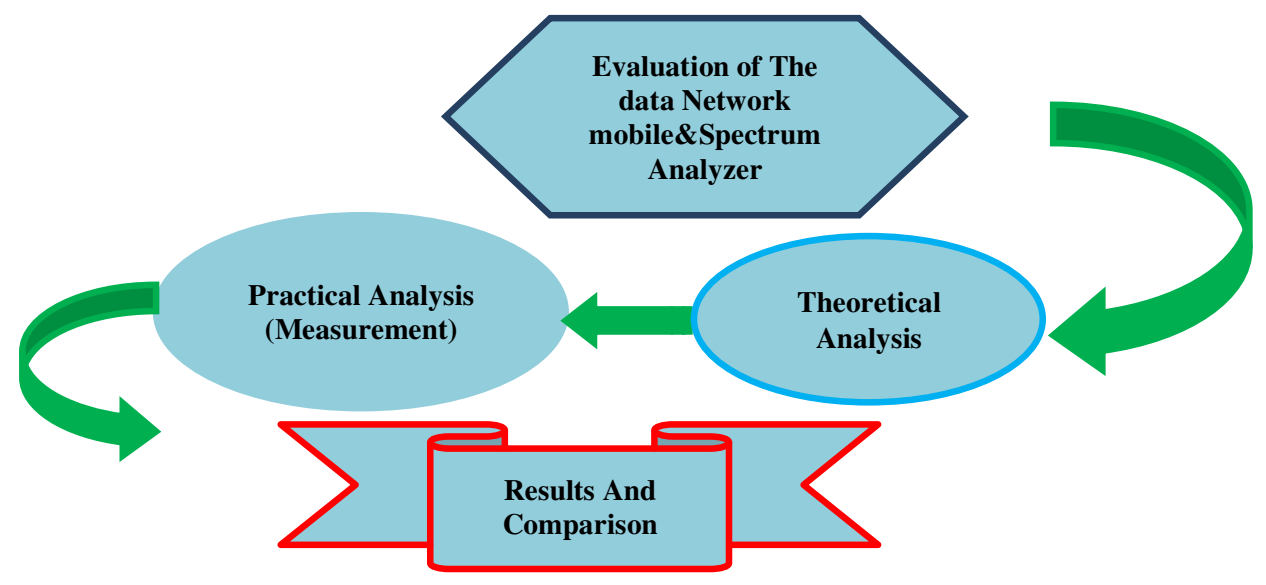

Figure. 1. Various Steps Carried-Out in This Research Paper 
International Journal of Computer Networks \& Communications (IJCNC) Vol.9, No.1, January 2017

\section{STUDY AND EVALUATION OF MOBILE NETWORK (DISADVANTAGES OF CELL PHONE )}

\subsection{Spectrum Packaging:}

There are many networks that are used in the standard (GSM) but at different frequencies. In the Republic of Yemen, we have three companies used GSM900 \& GSM-1800 system and one company using CDMA system (note that he will soon reek new company in Yemen). Thus, be a total of four companiesFrequency Range At Mobile systems

Table. 1 . Frequency Range At Mobile systems.

\begin{tabular}{|c|c|}
\hline Mobile systems & $\begin{array}{c}\text { Cell Tower Transmit } \\
\text { Frequency Bands }\end{array}$ \\
\hline GSM-1800 & $1810-1880 \mathrm{MHz}$ \\
\hline GSM-900 & $935-960 \mathrm{MHz}$ \\
\hline CDMA & $869-894 \mathrm{MHz}$ \\
\hline $3 \mathrm{G}$ & $2110-2170 \mathrm{MHz}$ \\
\hline$f=2450 \mathrm{MHz}$ is approximately the center frequency of \\
Wi-Fi, WLAN, Bluetooth, Microwave. \\
\hline
\end{tabular}

- Half is used for transmitting and the other half is used for receiving.

- Base station antenna transmits in the frequency range of $935-960 \mathrm{MHz}$.

- Frequency band of $25 \mathrm{MHz}$ is divided into twenty sub-bands of $1.2 \mathrm{MHz}$ (which are allocated to various operators).

- Several carrier frequencies allotted to one operator with upper limit of $6.2 \mathrm{MHz}$ bandwidth.

- Each band is subdivided into 124 carrier frequencies spaced $200 \mathrm{KHz}$ apart

From this information it is clear that each operator (operators) dedicated his $1.2 \mathrm{MHz}$ and there are several frequencies to transfer to the upper limit of the bandwidth $6.2 \mathrm{MHz}$ (bandwidth) may be more than four frequencies for the operator one (operator), and every single operator sends capability (100W - 50W ) as we have stated previously that in Yemen there are three companies use this system, which is typically used per tower or desktop architecture for several companies, and therefore, one operator will be moved from (300W-150W) almost or more.

As is emitted from the cell phone (MS) electromagnetic radiation frequency $900000000 \mathrm{~Hz}$ in the form of pulses, the time of each pulse is about 546 microseconds and the pulse repetition rate of 217 times per second, although exposure to electromagnetic waves from cell phone device takes the form of short pulses repeated her high-energy at a time the very short radiation emitted from the transmitting station Aberg be continuous and have a small capacity, for example, frequencies issued by Aberg fall in the range between $930-960 \mathrm{MHz}$, this radiation in each pulse has an active biological effects. The pulses emitted by cellular phone collide brain cells 217 times every second, leading to some ill effects suffered by users because the exposure be cumulatively on the human body. 


\subsection{MS Output Power}

There are multiple degrees from Mobile Phone device (MS) it has been scientifically classified according to how efficient (Maximum Output power). As shown in Table 2. The previous energy levels high and can be reduced depending on me specific commands sent by the network (GSM). This command works (MS) low energy levels and maintain an acceptable quality of the signal. Unfortunately, the energy levels are working on reduced depending on me specific commands sent by the network to maintain signal quality for the user and not the health of the user !!!

Table. 2 . GSM Mobile Station (MS) power classes

\begin{tabular}{|c|c|c|c|}
\hline $\begin{array}{c}\text { GSM } \\
\text { MS } \\
\text { Power } \\
\text { classes }\end{array}$ & $\begin{array}{c}\text { Nominal Max. } \\
\text { power(output) } \\
\text { GSM-400, GSM- } \\
\text { 900, GSM-850 }\end{array}$ & $\begin{array}{c}\text { Nominal Max. } \\
\text { power } \\
\text { (output) } \\
\text { DCS-1800 }\end{array}$ & $\begin{array}{c}\text { Nominal Max. } \\
\text { power } \\
\text { (output) } \\
\text { PCS-1900 }\end{array}$ \\
\hline Class-1 & $20 \mathrm{~W}(43 \mathrm{dBm})$ & $1 \mathrm{~W}(30 \mathrm{dBm})$ & $1 \mathrm{~W}(30 \mathrm{dBm})$ \\
\hline Class-2 & $8 \mathrm{~W}(39 \mathrm{dBm})$ & $0.25 \mathrm{~W}(24 \mathrm{dBm})$ & $0.25 \mathrm{~W}(24 \mathrm{dBm})$ \\
\hline Class-3 & $5 \mathrm{~W}(37 \mathrm{dBm})$ & $4 \mathrm{~W}(36 \mathrm{dBm})$ & $2 \mathrm{~W}(33 \mathrm{dBm})$ \\
\hline Class-4 & $2 \mathrm{~W}(33 \mathrm{dBm})$ & - & - \\
\hline Class-5 & $0.8 \mathrm{~W}(29 \mathrm{dBm})$ & - & - \\
\hline
\end{tabular}

It is obvious to any sane human being has a background in electrical and electromagnetic fields is aware that any device that emits a rate of half a watt $\mathrm{W}$ (more or less) on the subject of man hath permission negative impact printing. At the same time that this device is placed near the heart (in the upper pocket) or near the kidneys (in the pants pocket), and this device transmits over 1 watt (more or less) hath negative impact. From this simple premise is clear to us that there is the influence of the ability of the mobile phone transmitter. Add to that the nigeriawap finish off with a rating of SAR (Specific Absorption Rate). For example, in the United States, that is to reduce SAR $(1.6 \mathrm{~W} / \mathrm{Kg})$, which represents 6 minutes of daily use. From what means that a person should not use a cell phone for more than 18 to 24 minutes per month.The big problem that in the third world countries and we have the same in Yemen that the majority of people use mobile phones with a SIM card (GSM \& CDMA) and the mobile phone industry, of course, foreign companies is universally known. And therefore have value and the value of SAR (MS Output Power) has unknown and print as it is well-known companies, the value of SAR High may be very high, which produces them radiative forcing, which is divided into two sections:

1. Thermal effects (Thermal Effects): is similar to that of cooking in the microwave oven. 2. The non-thermal effects (Non- Thermal Effects): non-thermal effects are more harmful than thermal effects by 3 to 4 times and this is what has been reported about (though they are not nonthermal effects of the definition of the best of our knowledge).

Unfortunately that organizations look at the thermal effect and do not look to the non-thermal effects though it has sparked a health greater than the thermal effect and who became his influence is evident in the present era. 


\subsection{Cell Phones And Cell Phone Towers}

BTS (Base transceiver station) is responsible for the cell cover (call) which covers the cell a given frequency until the interference does not happen, and covers one geographic cell, and can be a cover cell minimum $8 \mathrm{~km}$, the maximum average $35 \mathrm{~km}$, and a maximum of $100 \mathrm{~km}$, these cells are classified by several the most important factors of population density. So the cell is divided into three areas:

1-UrbanArea:Which are areas that can contain many buildings, such as "built cities," or big cities. And earth elements are very important here as a result of the high level of congestion.

2- Suburban Area:Which areas may not be overcrowded, but it may be where villages or highways, and with a few trees and buildings. These elements may be more important to be taken into consideration in this type of environment.

3- Open Area:It can be a barrier-free zones, at least open between the sender and the future space. And be so slim earth elements are not taken into account.

\subsection{Adding Capacity}

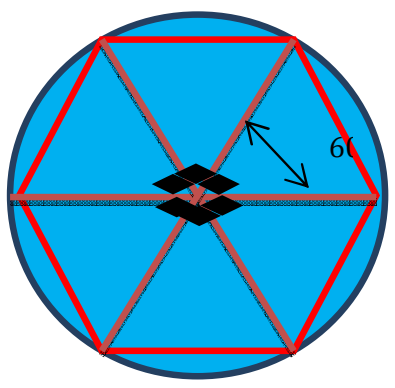

(a)

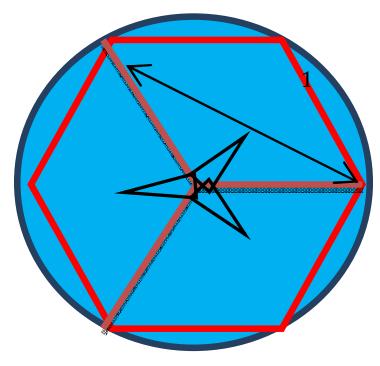

(b)

Figure. 2. (a) six sectors, (b) three sectors

In fact, the increasing the telephone traffic problems exist in cities in the regions or rather in cells (Urban Area), when there is a problem of increased telephone traffic in one of the cells that exceeds the maximum capacity, it is re-division of the cell to a number of small cells, each new cell needs Phones to the station (BS). Increasing the capacitance is typically accomplished by using small cells, the smaller the cell size, the space between cells that use the same telephone channels will be reduced, which leads to increased interference, it can reduce this capability to send ground station to control the impact of (BS) or mobile (MS). Practical way to reduce the interference level know Sectorisation sectors which use several antennas oriented rather than one antenna at the cellular station and there are two method:

The first method:The use of three antennas each antenna covers 120 degrees of the cell space which each cell split into three sectors and in this case will reduce the overall level of interference to the third. As shown in Figure 2.

The second method:Six antennas are used and the result will be if you use 7 cells and thus the level of overlap is reduced to approximately $1 / 6$. At the same time reduces the efficiency of the total telephone traffic.From the above it is clear that the most congested areas of the population density are more areas where the number of cells present (three-way or six-way) and that most of 
the towers mounted near residential buildings. Through ,We found that some of the towers violate the limits of safety standards and allowed these violations:

- That some cell towers that resides on one surface of the horizontal distance between them is less than 12 meters.

- Some of the towers on the cell surfaces that do not have a wall of non-metallic. Where the boundaries of safety standards indicate that you should put the wall is a metal from all directions on the six meters from the base of the tower center distance (so that the fence of metal material or metal is intended to determine safe distances to ensure not to approach the antennas). - Some cell towers $24 \times 7$ movement of radiation, to provide coverage of a sound network users and those who live or work in basements or buildings are deported almost 10 meters from the tower, so you will get a signal from 1,000 to 10,000 times stronger (at a minimum) than is required for mobile communications.

- Some cell towers carrying high rise buildings nearby. And that you should not go up all the neighboring buildings in a radius of ten met by the limits of safety standards.

There are some negative results that have been obtained through a theoretical analysis of the process and record the result of these irregularities.

\subsection{Radiation Pattern of the Antenna}

Radiation Pattern refers to the directional (angular) dependence of the strength of the radio waves from the antenna or other source. Specially in the fields of fiber optics, lasers, and integrated optics, the term radiation pattern may also be used as a synonym for the near-field pattern or Fresnel pattern.This refers to the positional dependence of the electromagnetic field in the nearfield, or Fresnel region of the source. Radiation model on the other hand is a three-dimensional volume includes field change or the ability (the ability commensurate with the Domain box as a function of spherical coordinates and proportional to the field strength in the direction of the corners career. The direction of the main lobe (main lobes) which is the direction of maximum radiation applies to the vertical axis (z) with sub-lobes or secondary (minor lobes) in the other directions.Horizontal pattern has to do with beam width and coverage area.the beam width in vertical pattern determines the power distribution over coverage.

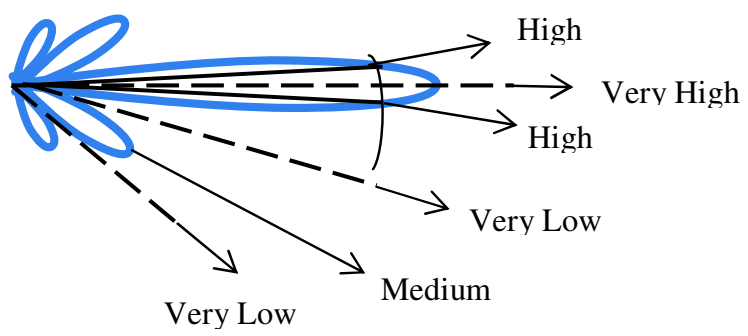

Figure. 3.Radiation Pattern of Cell Tower Antenna

To realize seamless coverage, the proper selection of BTS antenna parameters is of essential importance. As for GSM or CDMA BTS for digital mobile communication network, the selection of BTS antennas available at home is based upon the following principle Tilt angle. 
Tilt angle can be reached by the following formula:

$$
\alpha=\operatorname{arctg} h /(r / 2)
$$

Where:

$\boldsymbol{\alpha}$ - stands for tilt angle.

$h$ - height of antenna.

$r$ - the distance between base stations.

Antennas that are mounted on the roofs of buildings may be electrical or mechanical down tilt, so that the signals are directed towards the ground level (Antennas are tilted to direct the beam to the ground) According to the tilt angle (tilt angle).The design is the base station and power transmission in this way to provide good coverage for the user. Unfortunately there is a tendency to make the corners of the main beam (main beam) prompt so that they are supreme ability prompt directly to homes or offices.

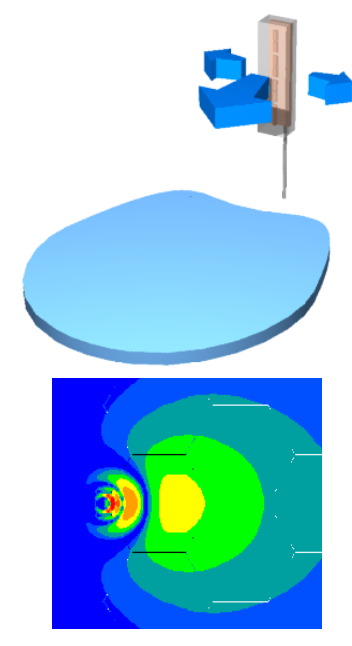

(a) no tilt

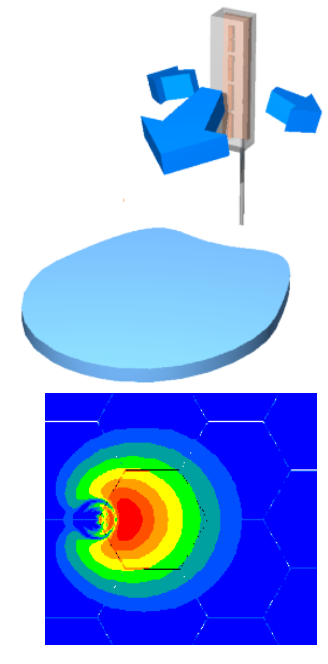

(b) $10^{\circ}$ electrical down tilt

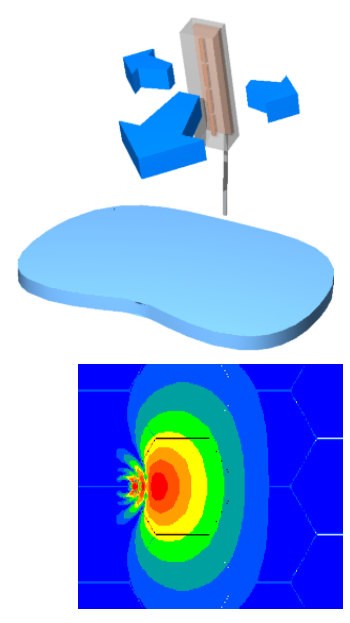

(c) $10^{\circ}$ mechanical tilt

Figure. 4.Comparison between three methods

\section{Mathematical Analysis and Practical Measurement}

Because the most important thing to find a good cover for the user, without taking into account the strength of the radiation and its impact on the user's health. Figure 4 shows an example of a comparison between the effectiveness of the coverage and the strength of the radiation in color when using tilt anglefor various types of antennas.

Of course, in most cells of the cellular communication networks are used directional antennas and the same cells in the (Urban Area) using a directional antenna. 


\subsection{Measured All-Signal Strength On Broadcast control channel Carrier in Urban Area} cell

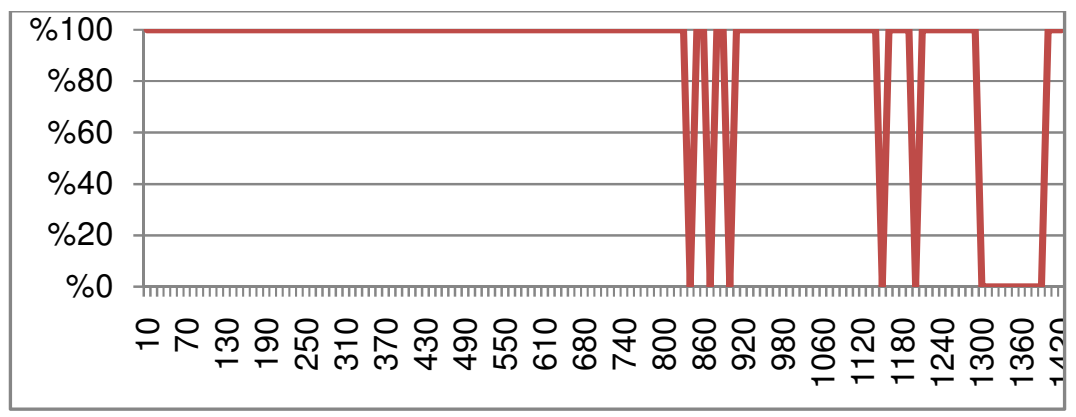

Figure. 5.The relationship between distance and All-Signal Strength On BCCH Carrier in Urban Area cell

\subsection{Measured the MS $T_{\mathrm{X}}$ Power $(\mathrm{dBm})$ in Urban Area cell}

The following shows us the ability to send a mobile compared to the distance from the cell, we find that the bladders of the cell or beyond the cell, the proportion of large transmission capacity and the (control power) mission signal quality for the user, not the user's health, noting that the figure 6 on the street and not in buildings, which means that the transmission capacity of the cellular phone is much larger when the mobile device in the buildings or inside our clothes, because the antenna device Nigeria wrap restricted by the walls and ceilings, or out of our clothes.

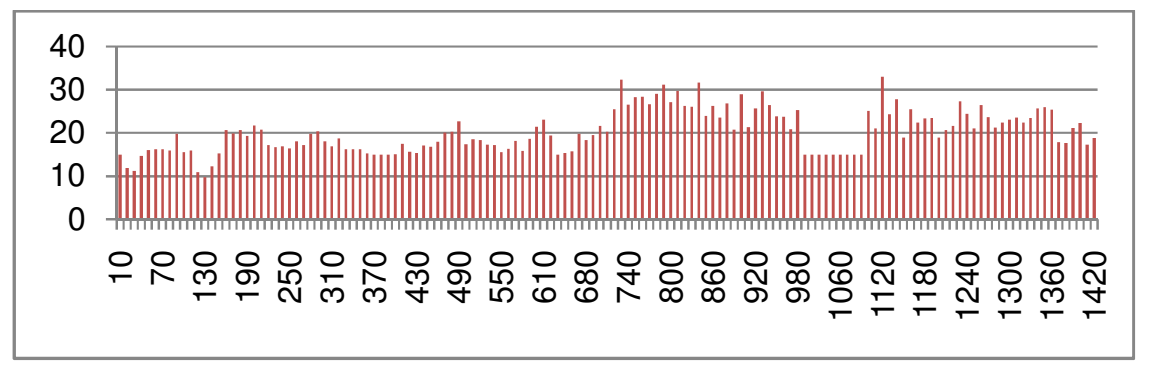

Figure. 6.The relationship between distance and $\mathrm{MS} \mathrm{T}_{\mathrm{X}}$ Power $(\mathrm{dBm})$ in Urban Area cell

The user of a mobile device is exposed to two types of radiant energy (non-energy radiation from cell towers):

1- receiving monopole antenna gain.

2- Electrical power transmitted inductively: It is the energy that moves as a result of the voltage of the device and emits effect of the device to the head and hands of the speaker. Stems biological effect of these radiations from three factors are frequency, power and time of exposure to radiation The influence of small energy in a long time exposure is equivalent to the impact of high energy in a short exposure time and when the frequency stability of the radiation source. 


\subsection{Radiated Power Density From The Cell Tower:}

Table. 3: radiation norms given by ICNIRP guidelines of 1998 for safe power

\begin{tabular}{|c|c|}
\hline Frequency range & Equivalent wave power density $\left(\mathbf{m W} / \mathbf{C m}^{2}\right)$ \\
\hline $10-400 \mathrm{MHz}$ & 0.2 \\
\hline $400-2000 \mathrm{MHz}$ & $f / 2000$ \\
\hline $2-300 \mathrm{GHz}$ & 1 \\
\hline
\end{tabular}

The prescribed safe RF exposure limitis $f / 2000$ (in Yemen), where $f$ isin MHz.

Exposure limitsinYemen are:

-for GSM-900 transmitting band $(935-960 \mathrm{MHz})$, power density is $4.7 \mathrm{~W} / \mathrm{m}^{2}$.

- for GSM-1800 transmitting band (1810-1880 MHz), it is $9.2 \mathrm{~W} / \mathrm{m}^{2}$.

Power density $P_{d}$ at a distance $r$ is given by

$$
P_{d}=\frac{P_{\mathrm{T}} G_{\mathrm{T}}}{4 \pi r^{2}} \quad\left(\mathrm{Watt} / \mathrm{m}^{2}\right)
$$

where,

$P_{T}$ - Transmitter power in Watts.

$G_{T}$ - Gain of transmitting antenna.

$r$-Distance from the antenna in meters.

Radio waves from base stations in Yemen comply with international health and safety guidelines. The exposure limit for the radio frequency field (Basestation) emissions prescribed by the Department of Telecom,Government of Yemen,isas Table. 3.

$$
G_{T}=17 d B=10^{\left(\frac{17}{10}\right)} W=50 W
$$

Table.4.Measured power density at various locations in the Urban Area cell

\begin{tabular}{|c|c|c|}
\hline $\begin{array}{c}\text { Distances } \\
r(\mathbf{m})\end{array}$ & \multicolumn{2}{|c|}{ Urban Area cell for GSM-900 } \\
\cline { 2 - 3 } & ${\boldsymbol{P} \boldsymbol{d}\left(\mathbf{W} / \mathbf{m}^{\mathbf{2}}\right)}_{\boldsymbol{P}_{\boldsymbol{d}}\left(\boldsymbol{\mu} \mathbf{W} / \mathbf{m}^{\mathbf{2}}\right)}$ \\
\hline 1 & 159.15 & 159.150 .000 \\
\hline 4 & $\mathbf{9 . 9 5}$ & $\mathbf{9 . 9 5 0 . 0 0 0}$ \\
\hline 8 & 2.49 & 2.490 .000 \\
\hline 10 & 1.59 & 1.590 .000 \\
\hline 15 & 0.707 & 707.000 \\
\hline 20 & 0.397 & 397.000 \\
\hline 25 & 0.255 & 255.000 \\
\hline 30 & 0.177 & 177.000 \\
\hline 40 & 0.099 & 99.000 \\
\hline
\end{tabular}


International Journal of Computer Networks \& Communications (IJCNC) Vol.9, No.1, January 2017

\begin{tabular}{|c|c|c|}
\hline 50 & 0.064 & 64.000 \\
\hline 80 & 0.025 & 25.000 \\
\hline 100 & 0.016 & 16.000 \\
\hline 200 & 0.00397 & 3.970 \\
\hline \multicolumn{3}{|c|}{ For $P_{T}=40 W, G_{T}=17 \mathrm{~dB}=50 \mathrm{~W}$} \\
\hline
\end{tabular}

\subsection{Effective Isotropic Radiated Power (EIRP):}

Energy density is above the value for the holder of one (single carrier) and operator of one single operator)). As we have stated previously that it is used per surface for several companies and we have four companies in Yemen. Therefore, the radiation intensity is much more than that. As shown in Table 4. And also note that the value of the energy density exceeds the above standards. Gaze on it, the safe distance for permanent display to the public, which have been calculated in paragraph 4.8. Outweigh the amount of space. Note that it requires a beam pattern ID (radiation) the actual, to find the exact value of the energy density at a certain point. Unfortunately, the actual radiation pattern of the antenna does not announce as attic !!!

We put in our consideration that the axis spherical where is the antenna in a ball center and the ability of general distribution uniform in all directions, and this is emitted from the antenna power in the direction of the main beam (Main Beam) as the gain (Gain) antenna estimated indoor $2 \mathrm{~dB}$ and about $16 \mathrm{~dB}$ (according to specifications technical stations outside the buildings where the out door to gain antennas ranging from $16-17 \mathrm{~dB}$ in the direction of the main beam (main beam) for transmission (outdoor is calculated as follows:

$$
\begin{gathered}
(\text { EIRP })=\text { Max. input power }+ \text { Antenna Gain } \\
=46+17=63 \mathrm{dBm}
\end{gathered}
$$

Despite the antenna radiates energy less vertically down, but you may have noticed that some of the distance between the antennas and upstairs is usually a few meters away, so the radiation level on the upper floor is too high. As shown Figure 8.

\section{5 . Radiation Influence The Public Through Continuous Exposure To Radiation:}

The ability to calculate the transmitters (the number of transmitters) and the maximum capacity. Assuming that the number of transmissions of four and maximum capacity for each of which devices are W50 to $100 \mathrm{~W}$ If we take the average maximum capacity each with $75 \mathrm{~W}$ we get Also, the power emitted by the antenna in the other directions (Other Directions) radiation in other directions which are (top and bottom and behind) the antenna less about dB20 from the main transmission direction. 


$$
\text { Total loss }=2 \mathrm{~dB} \text { (for Combiner })+1 \mathrm{~dB}(\text { for cable })=3 \mathrm{Db}
$$

The focus here that the above output to one terminal and one company. As we have stated previously that he could share several companies on a single surface. Because of the loss of conductivity caused by assembling transmitters output by the compound (Combiner) and the loss of it up to $6 \mathrm{~dB}$ in addition to a loss caused by conduction cables and connecting the loss of it to $4 \mathrm{~dB}$. Note that the conductive cables from room (BS) to antennas do not ten meters, while a few other cables have ten meters, no matter how we assume that the average loss $3 \mathrm{~dB}$. To illustrate the effect of radiation to the public through continuous exposure to radiation, can calculate the total income the ability of the antenna:

Maximum input power to the antenna $=54.8-3=51.8 \mathrm{dBm} \cong 52 \mathrm{dBm}$

and also note that they exceedthe standard is $46 \mathrm{dBm}$

\subsection{Measure Received Power}

A cell-site transmitter is transmitting at an average power level $P_{T}$. We want to find the received power level, $P_{R}$ at the receiving antenna (MS) located at a distance, $d$ from the transmitter. For an isotropic antenna:

$$
P_{R}=\frac{P_{T}}{4 \pi r^{2}}
$$

Where:

$P_{T^{-}}$average power level of transmitter.

$r$ - distance between transmitter and receiver

$P_{R^{-}}$power density at the receiver.

When a directional transmitting antenna with a power gain factor, $G_{T}$, is used, the power density at the receiver site is $G_{T}$ time's Eq. (1).

The amount of power captured by the receiver is $P_{R}$ times the aperture area, $A_{R}$, of the receiving antenna.

The aperture area is related to the gain of the receiving antenna by:

$$
G_{R}=\frac{4 \pi A_{R}}{\lambda^{2}}
$$


Where:

$$
\lambda=c / f
$$

$f$ - the transmitter frequency in $\mathrm{Hz}$.

$A_{R^{-}}$is the effective area, which is less than the physical area by an efficiency factor $P_{R}$.

Typical values for $P_{R}$ range from $60 \%$ to $80 \%$ percent. The total received, $P_{R}$, is:

$$
P_{R}=A_{R} P_{R}
$$

Substituting the value of $P_{R}$ and $A_{R}$ from Eq. (1) and (2) into Eq. (4) together with the transmitting antenna gain $G_{T}$, we get the Power Received $P_{r}$ by an antenna at a distance $d$ is given by:

$$
P_{R}=\left\{\frac{\lambda}{4 \pi r}\right\}^{2} P_{T} G_{T} G_{R}
$$

Table. 5. Measured Power received at different frequencies various locations in the Urban Area cell

\begin{tabular}{|c|c|c|c|c|c|c|}
\hline \multirow{2}{*}{$\begin{array}{c}\text { Distances } \\
\boldsymbol{r}(\mathrm{m})\end{array}$} & \multicolumn{2}{|c|}{$\begin{array}{c}\text { Urban Area cell for } \\
\text { GSM-900 } \\
\text { at } f=945 \mathrm{MHz})\end{array}$} & \multicolumn{2}{c|}{$\begin{array}{c}\text { Urban Area cell for } \\
\text { GSM-1800 } \\
\text { at } f=1872 \mathrm{MHz})\end{array}$} & \multicolumn{2}{c|}{$\begin{array}{c}\text { Urban Area cell for } \\
\text { CDMA } \\
\text { at } f=887 \mathrm{MHz})\end{array}$} \\
\cline { 2 - 7 } & $\boldsymbol{P}_{\boldsymbol{R}}(\mathrm{dBm})$ & $\boldsymbol{P}_{\boldsymbol{R}}(\mathrm{mW})$ & $\boldsymbol{P}_{\boldsymbol{R}}(\mathrm{dBm})$ & $\boldsymbol{P}_{\boldsymbol{R}}(\mathrm{mW})$ & $\boldsymbol{P}_{\boldsymbol{R}}(\mathrm{dBm})$ & $\boldsymbol{P}_{\boldsymbol{R}}(\mathrm{mW})$ \\
\hline 20 & 7.016 & 5.03 & 1.07 & 1.28 & 7.57 & 5.72 \\
\hline 40 & 1 & 1.26 & -4.9 & 0.32 & 1.547 & 1.428 \\
\hline 60 & -2.53 & 0.558 & -8.5 & 0.142 & -1.97 & 0.635 \\
\hline 80 & -5.027 & 0.314 & -10.9 & 0.08 & -4.47 & 0.357 \\
\hline 100 & -6.98 & 0.20 & -12.9 & 0.051 & -6.42 & 0.228 \\
\hline For $P_{T}=40 \mathrm{~W}=46 \mathrm{dBm}, G_{T}=17 \mathrm{~dB}$ and $G_{R}=2 \mathrm{~dB}$ (receiving monopole antenna gain) \\
\hline
\end{tabular}

The most important criteria is the received signal level (RX-Lev) and received signal RX-Qual)) is the power of the quality of the received signal in $\mathrm{dBm}$ unit. It uses (RX-Lev) to determine the quality of a voice call through the value of the RX-Lev. Has usually been the minimum for the RX-Lev accepted the appointment of $-104 \mathrm{dBm}$ of the cell. 


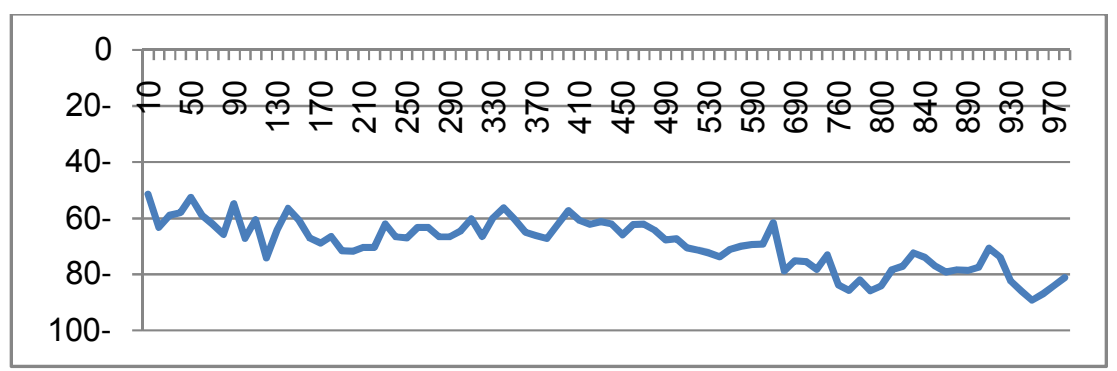

Figure. 7.Measured $\mathrm{R}_{\mathrm{X}}-\mathrm{Lev}(\mathrm{dBm})$ at various locations in The Urban Area cell

While it considered the value of RX-Lev dBm -70 very good value for the customer to be able to access the network, so it is highly recommended that there be adequate coverage with acceptable quality As it is shown in Figure7.

\subsection{Measured Total Received Power At The Apartment, Which On The Surface Cellular Station:}

Radiation measurements in the apartment, which on the surface cell towers were in violation of the standards in terms of space after the towers from each other so it's less than 12 meters, and its distance from the surface wall of less than six meters from the base of the tower center. It is among the offenses that we have found contrary to the standards of safety limits, which have been noted in paragraph 3.4. Measurement readings showed that the radiation level is very high, as shown in Figure 8. As we know that the radiation on the human body effect is cumulative.

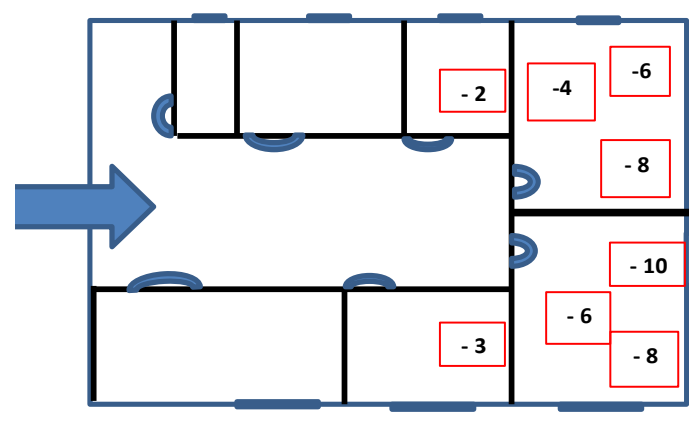

Figure. 8. The total received power in $\mathrm{dBm}$, At $900 \mathrm{MHz}$

\subsection{Safety Distance Calculation}

To calculate the safe distance constant exposure to the public safety distance is calculated as follows:

$$
\text { Standard Isotropic Power Density }(S I P D)=\frac{E I R P}{4 \pi D^{2}}
$$

Safe distance (D) is calculated from the following relationship:

$$
D=\sqrt{\frac{E I R P}{4 \pi(S I P D)}}
$$


International Journal of Computer Networks \& Communications (IJCNC) Vol.9, No.1, January 2017

-USA Specifications:

States that do not increase the ability emitted from $0.57 \mathrm{~mW} / \mathrm{Cm} 2$

$$
\mathrm{D}_{\text {main }}=\sqrt{\frac{E I R P}{4 \pi\left(0.57 \mathrm{~mW} / \mathrm{Cm}^{2}\right)}} \cong 374 \mathrm{~cm}=3.74 \mathrm{~m}
$$

\section{-The ICNIRPSpecifications:}

It stipulates that no more than the amount of radiation intensity from $0.4 \mathrm{~mW} / \mathrm{Cm} 2$ as follows:

$$
\mathrm{D}_{\text {main }}=\sqrt{\frac{E I R P}{4 \pi\left(0.4 m W / \mathrm{Cm}^{2}\right)}} \cong 446 \mathrm{~cm}=4.46 \mathrm{~m}
$$

\section{CONCLUSION}

Finally, line is that there are health risks as a result of radiation from cell phones and cell towers due to some irregularities with international standards ,or the total radiation has also been explained by the results we have obtained.

Although the results were negative energy density, but it requires the beam pattern ID (radiation) the actual, to find the exact value of the energy density at a certain point. Unfortunately, the actual radiation pattern of the antenna does not announce attic !!!

So must all international organizations never of ICNIRP and WHO „, FCC, etc. The guidelines are that the exposure, taking taken simultaneously to multiple sum of all radiation into account the frequency fields into account exposure to the sum of these radiation 24 hours a day (the houses) or eight hours a day (offices) and not a single beam. At the same time it has to look at the effects of these non-thermal radiation because it has sparked a health greater than the thermal effect and who became his influence is evident in the present era. Several studies have shown that the non-thermal effects occur at much lower levels in these rules. They should be tougher standards, as we know that in addition to the continuous radiation from cell towers, there is radiation from mobile phones and cellular phones and FM and AM and towers ........ As is well known that the source of the biological effect of these radiations of three factors are frequency, power and time of exposure to radiation the influence of small energy in a long time exposure is equivalent to the impact of high energy in a short exposure time and when the frequency stability of the radiation source.

\section{References}

[1] Nathan Lawrentschuk and Damien M Bolton, Mobile phone interference with medical equipment and its clinical relevance: a systematic review, Systemic Review https://www.mja.com.au/public/issues/181_03_020804/law10022_fm.pdf

[2] SantiniR,SantiniP,DanzeJM,LeRuzP,SeigneM,Study of the health of people living in the vicinity of mobile phone base stations:Incidence according to distance and sex, Pathology Biology,50(6),36973,200227http://www.bevolution.dk/pdf/SantiniEnglishBevolution.pdf

[3] Study of cell tower radiation and its health hazards on human body,LalrintharaPachuau1, Zaithanzauv aPachuau,IOSR Journal of Applied Physics(IOSR-JAP)2014. 
International Journal of Computer Networks \& Communications (IJCNC) Vol.9, No.1, January 2017

[4] Effects of electromagnetic radiations from cell phones:A critical study,Sanjeev Dhawana, Kulvinder Singh Handa,InternationalJournalof Engineering,Business and Enterprise Applications(IJEBEA)2012.

[5] Humanbra in with EMR of cell phones,G.A. Bhalerao,Prof.R.G.Zope,G.B.Khaire,B.P. Tambe,International Journal of Modern Engineering Research(IJMER)2013.

[6] Mobile phone radiation effects on human health, BhargaviK,KEBala chandrudu,NageswarP, International Journal of Computational Engineering Research 2013.

[7] Effects of mobile phone and mobile phone tower radiations on human health,Mustaq Ahmed,Vijay Kumar,Gupta G.K.,International Journal of Recent Scientific Research,September 2013.

[8] Investigation and analysis on electromagnetic radiation from cellular base station transmitters and the implications to human Body,OperaK. Felix,Adigwe U.Gabriel,AgbarajiC. Emmanuel,Journal of Environment and Ecology 2014.

[9] Study of cell tower radiation and its health hazards on human body,Lalrinthara Pachuau1, ZaithanzauvaPachuau,IOSR Journalof Applied Physics(IOSR-JAP)2014.

[10] Effects of basestation radiations in Sudan, Ahmed Freabi Mohammed Ahmed,Amin BabikerA/NabiMustafa,International Journal of Science and Research(IJSR) 2015.

[11] Radio frequency interference with medical devices. COMAR technical information statement,IEEE Engineering in Medicine and Biology Magazine. 1998, 17(3):111-114http://ewh.ieee.org/soc/embs/comar/interfer.html

[12] Biological And Health Effects Of Exposure To Electromagnetic Field From Mobile Communications Systems; Masao TAKI, Soichi WATANABE; August 20, 2001; Mobile Communication In Transport.

[13] European Commission; health \& consumer protection directorate-general. scientific committee on emerging and newly identified health risks (scenihr) Preliminary Opinion on Possible effects of Electromagnetic Fields (EMF) on Human Health,19 July 2006.

[14] Foletti A, Lisi A, Ledda $M$ et al. (2009). Cellular ELF signals as a possible tool ininformative medicine. Electromagnetic Biology and Medicine. 28 (1), 71-79.

[15] Tian F, Nakahara T, Yoshida M, Honda N, Hirose H, Miyakoshi J. (2002). Exposure to power frequency magnetic fields suppresses X-ray-induced apoptosis transiently in Ku80-deficient xrs5cells. Biocemical and Biophysical Research Communications 292 (2), 355-361. 